\title{
Genetic polymorphism in "mixed" colonies of wood ants (Hymenoptera: Formicidae) in southern Finland and its possible origin
}

\author{
Julita KORCZYŃSKA ${ }^{1}$, Marta GAJEWSKA ${ }^{2 *}$, MalgorZata PILOT², Wojciech CZECHOWSKI ${ }^{2}$ \\ and AlEXANDER RADCHENKO ${ }^{2}$

\begin{abstract}
${ }^{1}$ Laboratory of Ethology, Nencki Institute of Experimental Biology, Polish Academy of Sciences, Pasteura 3, 02-093 Warsaw, Poland; e-mail: j.korczynska@nencki.gov.pl

${ }^{2}$ Museum and Institute of Zoology, Polish Academy of Sciences, Wilcza 64, 00-679 Warsaw, Poland; e-mails:mpilot@miiz.waw.pl,wcz@miiz.waw.pl, agradchenko@hotmail.com
\end{abstract}

Key words. Ants, Formica rufa-group, mixed colonies, hybridisation, genetic polymorphism

\begin{abstract}
Wood ant colonies that appear to consist of individuals representing different species are described in several previous papers. The present study is the first to elucidate the genetic basis of the spectacular morphological variability observed within such colonies. Two seemingly mixed colonies (FM-1 and FM-2) from southern Finland were investigated. On the basis of the morphology of their workers these colonies were comprised of individuals with phenotypes typical of Formica rufa L., F. polyctena Först., and $F$. aquilonia Yarr. The sequence of an mtDNA fragment (5' end of the cytochrome b gene) was used to examine the phylogenetic relationships among haplotypes of workers from homogeneous colonies of different wood ant species and the two supposedly mixed colonies, and to sort the individuals within the colonies into matrilines. Six microsatellite loci were used to analyse the genetic differentiation between colonies and among workers within colonies, and to detect putative hybrids. The results show that, independently of their phenotype, workers from the "mixed" colonies were genetically more similar to other individuals in their colony than to those in the homogeneous $F$. rufa, F. polyctena or F. aquilonia colonies. However, while colony FM-1 consisted of offspring of the same queen or more likely several maternally related queens, colony FM-2 consisted of the offspring of at least four unrelated queens. The data suggest hybridisation between $F$. polyctena $\times F$. aquilonia and $F$. polyctena $\times F$. rufa (and possibly subsequent mating between these hybrids) as the most probable mechanism leading to the existence of these two colonies, which implies that the hybrids are fertile. This study shows that colonies of wood ant hybrids can arise spontaneously and persist under natural conditions. The results also revealed that even some morphologically homogeneous colonies are genetically heterogeneous. In the case of closely related, morphologically similar species that interbreed, morphology can be a bad predictor of genetic differences between individuals.
\end{abstract}

\section{INTRODUCTION}

Wood ants, i.e. representatives of the subgenus Formica s. str. in general, and particularly members of the $F$. rufa-group, although well studied (see e.g. Cotti, 1963; Beretta Boera, 1979; Gösswald, 1989; Czechowski, 1996), still pose taxonomic problems and often puzzle field researchers. The $F$. rufa-group sensu Dlussky (1967) originally included four species of wood ants: $F$. rufa L., $F$. polyctena Först., F. aquilonia Yarr., and F. lugubris Zett. Formica paralugubris Seifert, a subsequently described sibling species of $F$. lugubris (Seifert, 1996a), is now accepted as a member of the same group. A quarter of a century ago, Vepsäläinen \& Pisarski (1981) called the F. rufa-group "a taxonomic enfant terrible" among wood ants and described the state of its taxonomy as "chaos before order". So far these vivid expressions have lost none of their relevance.

Not infrequently, colonies of wood ants are found in which the species status is practically indeterminable based on the commonly accepted morphological criteria (see e.g. Yarrow, 1955; Dlussky, 1967; Kutter, 1977;
Collingwood, 1979; Douwes, 1981; Seifert, 1996b; Czechowski et al., 2002). Workers from the same nest can exhibit intermediate species characters or appear to represent different species. In addition, the appearance of workers within a colony may change over time and samples taken from the same nest in different years may be classified differently (Pamilo \& Vepsäläinen, 1977; Vepsäläinen \& Pisarski, 1981; Czechowski, 1996). Recent investigations have cast some light on this conundrum. On one hand, there is now some evidence supporting the possibility of interspecific hybridisation within the F. rufa-group (e.g. Seifert, 1991, 1999; Czechowski, 1996; Goropashnaya et al., 2004; Gyllenstrand et al., 2004; Seifert \& Goropashnaya, 2004; Sorvari, 2006), while on the other hand, there are data that reveal the occurrence of temporary social parasitism within the subgenus Formica s. str., i.e. colonies that are taken over by heterospecific queens (see e.g. Pisarski \& Czechowski, 1994; Czechowski, 1996). The latter phenomenon would result in temporarily mixed colonies.

Nevertheless, not all cases encountered in the field seem to be the result of one of the above processes. Some

\footnotetext{
* Current address: Maria Sklodowska-Curie Memorial Cancer Center and Institute of Oncology, W.K. Roentgena 5, 02-781 Warsaw, Poland; e-mail: mgajewska@coi.waw.pl
} 

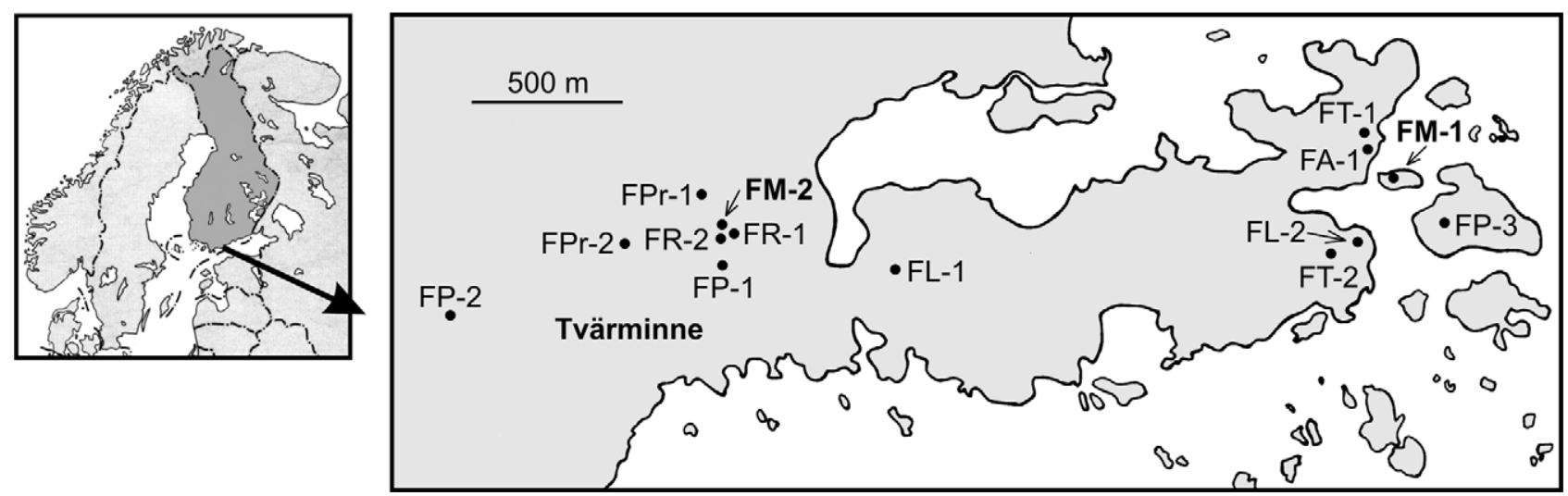

Fig. 1. Maps showing the location and the distribution of the Formica colonies studied. FM-1 - "mixed" colony 1; FM-2 "mixed" colony 2; FR-1 and FR-2 - colonies 1 and 2 of F. rufa; FP-1, FP-2, and FP-3 - colonies 1, 2, and 3 of F. polyctena; FA-1 colony of $F$. aquilonia; FL-1 and FL-2 - colonies 1 and 2 of $F$. lugubris; FPr-1 and FPr- 2 - colonies 1 and 2 of $F$. pratensis; FT-1 and FT-2 - colonies 1 and 2 of F. truncorum.

colonies seem to permanently consist of individuals of different species. Recently, two such supposedly polygynous colonies were observed in southern Finland. Their visibly mixed nature was revealed by an examination of the morphology of the workers and, in one of these cases, also of the young sexuals (males and alate queens) (Czechowski \& Radchenko, 2006). The aim of the present study was to characterise the genetic differentiation in these mysterious colonies and determine the origin of their spectacular morphological heterogeneity and to show whether morphology is really a good predictor of genetic differences in ants under discussion.

\section{MATERIAL AND METHODS}

\section{Study area and ant sampling}

The region of the Hanko Peninsula in southern Finland (Fig. 1 ) is well known for the unusually frequent and often unaccountable inter- and intracolonial variability in wood ants of the F. rufa-group (see Czechowski, 1996). From this region, and more specifically, from the Tvärminne archipelago and the vicinity of Tvärminne village, Czechowski \& Radchenko (2006) reported two colonies, FM-1 and FM-2, which, based on the morphology of workers (and in the case of FM-1 also the alate queens and males), were recognised as tri-species mixed colonies of Formica aquilonia, F. polyctena, and F. rufa. The prevailing phenotypes were typical of $F$. polyctena in FM-1 and $F$. rufa in FM-2. The mixed nature of FM-1 persisted much longer than the maximum longevity of workers. This was supported by an analysis of samples taken from the same nest in successive years from 2002 to 2008 . During this period the proportions of the "species" remained relatively stable $(65-84 \% F$. polyctena, $14-31 \%$ F. aquilonia, $1-7 \%$ F. rufa workers). The details of the morphology of the individuals as well as "species" composition of FM-2 are in Czechowski \& Radchenko (2006).

Workers from these two "mixed" colonies were subjected to genetic analyses. Nest samples were taken for this purpose in 2004. At this time, the proportions of the phenotypes rufa: polyctena : aquilonia in colonies FM-1 and FM-2 were 4\%: 65\% : $31 \%$ and $58 \%: 38 \%: 4 \%$, respectively (Czechowski \& Radchenko, 2006). Representatives of each phenotype were selected from the nest samples ( $\mathrm{n}>100$ for each colony), their morphology investigated (see Czechowski \& Radchenko, 2006) and then preserved in $96 \%$ ethanol. Individuals were classified into morphological groups corresponding to the different species based on commonly accepted key criteria, especially the presence, numbers, and appearance of standing hairs on the occipital margin of the head, the ventral surface of the head, and the pilosity on the dorsal part of the alitrunk (see e.g. Dlussky, 1967; Dlussky \& Pisarski, 1971; Collingwood, 1979; Seifert, 1996b; Czechowski et al., 2002). Specimens that were morphologically typical of a particular species were chosen for genetic analysis. In the case of the $F$. polyctena and $F$. rufa phenotypes, which were represented by a continuous transition from those with the typical external appearance of $F$. polyctena to that of $F$. rufa, "typical of a particular species" meant individuals that were either hairless or very hairy. The aquilonia phenotype was homogeneous and included workers that corresponded completely to the phenotype of this species (see Czechowski \& Radchenko, 2006).

We also collected samples from nests of "pure" colonies of $F$. rufa (2 nests), F. polyctena (3 nests), and $F$. aquilonia (1 nest), which were present in the same region and could be a potential source of individuals for the mixed colonies. Additionally, nest samples of other wood ant species occurring in the area: $F$. lugubris ( 2 nests), F. pratensis Retz. (2 nests), and $F$. truncorum F. (2 nests), were included in the analysis. They were used to further support the hypothesis that the mixing/hybridisation phenomenon studied involved only three species: $F$. rufa, $F$. polyctena, and $F$. aquilonia. They also served as outgroups in the phylogenetic analyses.

The colonies with workers morphologically typical of a given species and also morphologically homogeneous within the colony were selected from among numerous wood ant colonies present in the area. All the 14 colonies studied, both the "mixed" ones and those sampled for comparison, were situated quite close to each other. The greatest distance between the nests was ca. $3.5 \mathrm{~km}$ (Fig. 1).

A total of 72 workers were used in the analysis: 5 FM-1R, 5 FM-1P, 5 FM-1A ("mixed" colony FM-1: phenotypes of $F$. rufa, $F$. polyctena, and $F$. aquilonia, respectively), 6 FM-2R, 6 FM-2P, 5 FM-2A ("mixed" colony FM-2: phenotypes of $F$. rufa, F. polyctena, and $F$. aquilonia), 5 FR-1, 5 FR-2 (colonies 1 and 2 of F. rufa), 5 FP-1, 5 FP-2, 7 FP-3 (colonies 1, 2, and 3 of $F$. polyctena), 5 FA-1 (colony of $F$. aquilonia), 2 FL-1, 1 FL-2 (colonies 1 and 2 of $F$. lugubris), 2 FPr-1, 1 FPr-2 (colonies 1 and 2 of $F$. pratensis), 1 FT-1 and 1 FT-2 (colonies 1 and 2 of $F$. truncorum). For a map of the relative locations of the colonies studied see Fig. 1. 


\section{Methods}

Total genomic DNA was extracted from the body of each individuals using the DNeasy Tissue Kit (Qiagen Gmbh, Hilden, Germany). To reduce the likelihood of contamination with prey DNA from the alimentary tract, abdomens were removed before the genomic DNA was extracted. Two kinds of molecular markers were chosen for the genetic analyses: (1) a fragment of mitochondrial DNA (mtDNA) and (2) six microsatellite loci of nuclear DNA. The mtDNA fragment was used to analyse phylogenetic relationships among haplotypes of individuals from the "mixed" colonies and the colonies of different species, and to sort the individuals from the "mixed" colonies into matrilines. Microsatellite loci were used to analyse genetic differentiation between colonies and among workers within colonies, and detect putative hybrids.

The mtDNA fragment including the 5 ' end of the cytochrome b gene was amplified by PCR using primers CB-11059 and CB11449 (Goropashnaya et al., 2004). The reaction was performed in a total volume of $50 \mu \mathrm{l}$ containing $2 \mu \mathrm{l}$ of template DNA, $2 \mu \mathrm{l}$ of each primer $(10 \mathrm{pmol}), 250 \mathrm{mM} \mathrm{KCl}, 7.5 \mathrm{mM} \mathrm{MgCl}, 300$ $\mathrm{mM}$ Tris ( $\mathrm{pH} 8.4$ ), $10 \mathrm{mM}$ dNTPs (Sigma-Aldrich, St. Louis, MO, USA), and 2 U REDTaq Polymerase (Sigma-Aldrich, St. Louis, MO, USA). The reaction conditions for the amplification were: $2 \mathrm{~min}$ at $95^{\circ} \mathrm{C}$, then 35 cycles of $15 \mathrm{~s}$ at $94^{\circ} \mathrm{C}, 20 \mathrm{~s}$ at $48^{\circ} \mathrm{C}, 1 \mathrm{~min}$ at $72^{\circ} \mathrm{C}$, followed by $5 \mathrm{~min}$ at $72^{\circ} \mathrm{C}$. Amplified products were purified using the QIAquick PCR Purification Kit (Qiagen Gmbh, Hilden, Germany) and then sequenced using the individual PCR primers with a CEQ ${ }^{\mathrm{TM}} 8000$ (Beckman Coulter, Fullerton, CA, USA) automated DNA sequencer. In total 341 base pairs were scored for each of the 71 individuals. For one out of the 72 samples sequencing was unsuccessful.

The analysis of mtDNA variability was performed using the 71 sequences obtained in this study plus 41 orthologous Formica sequences from the NCBI database: $7 F$. rufa (FR), $9 F$. polyctena $(\mathrm{FP}), 10 \mathrm{~F}$. aquilonia $(\mathrm{FA}), 5 \mathrm{~F}$. lugubris (FL), $2 \mathrm{~F}$. pratensis $(\mathrm{FPr}), 2$ F. truncorum $(\mathrm{FT}), 2 \mathrm{~F}$. paralugubris $(\mathrm{FPl}), 2$ $F$. frontalis Santschi [FFr; an Iberian endemic species related to F. truncorum (see Tinaut \& Martínez, 1998)], and 2 F. (Serviformica) candida $\mathrm{F}$. Smith $(\mathrm{FCa})$. The sequences were retrieved and compared using BLAST, aligned using Clustal W (Thompson et al., 1994), and then the alignment was checked visually.

Phylogenetic relationships among the identified haplotypes were analysed using PAUP (Swofford, 1998). To choose the most appropriate model of sequence evolution, a hierarchical likelihood ratio test implemented using the program Modeltest (Posada \& Crandall, 1998) was performed. Based on the model $\mathrm{HKY}+\Gamma$ with the parameters estimated by Modeltest, a maximum likelihood tree was constructed. In addition, neighbour joining and minimum evolution trees were constructed, based on the model $\mathrm{HKY}+\Gamma$ and maximum likelihood distances estimated by Modeltest. All these trees were constructed using the program PAUP and the heuristic search algorithm. PAUP was also used to construct maximum parsimony trees. All phylogenetic trees were rooted by sequences of $F$. candida. Confidence in the estimated relationships was determined using the bootstrap approach (Felsenstein, 1985). Bootstrap values were obtained based on 1000 replicates and using the heuristic search algorithm implemented in PAUP.

The statistical parsimony approach implemented in the software TCS (Clement et al., 2000) was used to construct a network of phylogenetic relationships among haplotypes, with six mutational steps for $95 \%$ parsimonious connection. The network was nested according to rules described by Templeton et al. (1992) and Templeton \& Sing (1993).
Microsatellite variation was analysed at six loci: FE8, FE13, FE16, FE17, FE37, and FE42 (Gyllenstrand et al., 2002). PCR amplification was carried out in $20 \mu \mathrm{l}$ volumes containing $2 \mu \mathrm{l}$ of template DNA, $2 \mu 1$ of primers, and $10 \mu 1$ Multiplex PCR Kit (Qiagen Gmbh, Hilden, Germany) under reaction conditions: 15 min at $95^{\circ} \mathrm{C}$, then 16 cycles of $30 \mathrm{~s}$ at $94^{\circ} \mathrm{C}, 90 \mathrm{~s}$ at $58^{\circ} \mathrm{C}$, and $60 \mathrm{~s}$ at $72^{\circ} \mathrm{C} ; 10$ cycles of $30 \mathrm{~s}$ at $94^{\circ} \mathrm{C}, 90 \mathrm{~s}$ at $57^{\circ} \mathrm{C}$, and $60 \mathrm{~s}$ at $72^{\circ} \mathrm{C} ; 10$ cycles of $30 \mathrm{~s}$ at $94^{\circ} \mathrm{C}, 90 \mathrm{~s}$ at $55^{\circ} \mathrm{C}$, and $60 \mathrm{~s}$ at $72^{\circ} \mathrm{C}$, followed by $30 \mathrm{~min}$ at $60^{\circ} \mathrm{C}$. Fragment analysis was performed using a $\mathrm{CEQ}^{\mathrm{TM}} 8000$ (Beckman Coulter, Fullerton, CA, USA) automated DNA sequencer.

The GENEPOP software package (Raymond \& Rousset, 1995) was used to calculate observed heterozygosity $\left(H_{O}\right)$, expected heterozygosity $\left(H_{E}\right)$ (Nei, 1978), inbreeding coefficient $\left(F_{I S}\right)$, and test for Hardy-Weinberg equilibrium and population differentiation (Goudet et al., 1996). GENEPOP was also used to calculate fixation index $\left(F_{S T}\right)$ between pairs of phenotypes and pairs of colonies.

The assignment test and detection of first generation migrants were performed using the program GeneClass2 (Piry et al., 2004). The test was used to assign each individual to the colony and the phenotypic group to which it was genetically most similar. This allowed determination of whether "mixed" colonies constituted groups of genetically related individuals or simply assemblages of unrelated individuals from three different species. For each individual, the probability that it did not descend from the colony where it was collected was calculated using a test for detecting first generation migrants. This test allowed us to detect immigrants (i.e., individuals with a foreign genotype that were not born in a given colony) and their offspring (e.g., offspring of a local queen and a male of a different species). For each individual, the probability that it genetically fits its own phenotypic group was also calculated. This allowed us to detect individuals that were genetically more similar to individuals of a phenotype other than their own. Both the assignment test and that for detecting first generation migrants were performed using the Bayesian method of Rannala \& Mountain (1997) and the Monte-Carlo re-sampling algorithm of Paetkau et al. (2004) with 1000 simulated individuals and a type I error rate of 0.01 .

To determine whether the species of wood ants defined based on morphology are genetically well differentiated, we performed an analysis of population genetic structure based on frequencies of microsatellite alleles using software Structure 2.0 (Pritchard et al., 2000). This test was performed (1) without any prior information about individuals and (2) with individuals grouped according to their phenotype. We ran the analyses with a burn-in period of 10,000 MCMC replications and 100,000 replications after burn-in, and repeated each analysis three times. We used a model with population admixture and independent allele frequencies among populations.

\section{RESULTS}

Among the 71 sequenced samples, 10 mtDNA haplotypes (GenBank accession numbers: FJ623067, FJ623068, FJ623069, FJ623070, FJ623071, FJ623072, FJ623073, FJ623074, FJ623075, and FJ623076) were identified (Table 1). The analysed sequence (the 5' end of the cytochrome b gene) comprised 341 base pairs, which contained $9(3 \%)$ polymorphic sites. No insertions/deletions were found. The haplotypes differed in 1-9 base pairs. The average nucleotide composition was: $41.4 \% \mathrm{~T}$, $32.1 \% \mathrm{~A}, 14.6 \% \mathrm{C}$, and $11.9 \% \mathrm{G}$. In most colonies only one haplotype was found, but in colony FP-1 and "mixed" colony FM-2 there were two and four 
TABLE 1. Frequency of mtDNA haplotypes (\% of individuals with a given haplotype) in colonies and phenotypic groups within mixed Formica colonies; n - group size. Phenotype codes: FM-1 - "mixed" colony 1; FM-2 - "mixed" colony 2; FR-1 and FR-2 - colonies 1 and 2 of F. rufa; FP-1, FP-2, and FP-3 - colonies 1, 2, and 3 of $F$. polyctena; FA-1 - colony of $F$. aquilonia. For details, see last paragraph of Study area and ant sampling.

\begin{tabular}{|c|c|c|c|c|c|c|c|c|c|c|}
\hline \multirow{2}{*}{$\begin{array}{l}\text { Colony, } \\
\text { phenotype }\end{array}$} & \multirow[b]{2}{*}{$\mathrm{n}$} & \multicolumn{9}{|c|}{ Haplotypes } \\
\hline & & H1 & $\mathrm{H} 2$ & $\mathrm{H} 3$ & $\mathrm{H} 4$ & $\mathrm{H} 5$ & H6 & $\mathrm{H} 7$ & $\mathrm{H} 8$ & H9 H10 \\
\hline$\overline{\text { FM-1R }}$ & 5 & & & & & & & & & 100 \\
\hline FM-1P & 5 & & & & & & & & & 100 \\
\hline FM-1A & 5 & & & & & & & & & 100 \\
\hline FM-2R & 6 & & & 100 & & & & & & \\
\hline FM-2P & 6 & & 66.67 & & 16.67 & & 16.67 & & & \\
\hline FM-2A & 5 & & & 100 & & & & & & \\
\hline FR-1 & 5 & 100 & & & & & & & & \\
\hline FR-2 & 5 & 100 & & & & & & & & \\
\hline FP-1 & 5 & & 20 & & & & & & & 80 \\
\hline FP-2 & 5 & & & & & & & & & 100 \\
\hline FP-3 & 6 & & & & & & & & & 100 \\
\hline FA-1 & 5 & & & & & & & & 100 & \\
\hline FL-1 & 2 & & & & & & & & 100 & \\
\hline FL-2 & 1 & 100 & & & & & & & & \\
\hline FPr-1 & 2 & & & & & 100 & & & & \\
\hline FPr-2 & 1 & & & & & 100 & & & & \\
\hline FT-1 & 1 & & & & & & & 100 & & \\
\hline FT-2 & 1 & & & & & & & 100 & & \\
\hline
\end{tabular}

haplotypes, respectively. All individuals from "mixed" colony FM-1, independent of the phenotype, had the same haplotype (H9) as that of $F$. polyctena colonies FP-2 and FP-3. In colony FM-2, workers with phenotypes of $F$. rufa and $F$. aquilonia had the same haplotype (H3), but workers of the $F$. polyctena phenotype had three other haplotypes ( $\mathrm{H} 2, \mathrm{H} 4$, and $\mathrm{H} 6)$, two of them unique (Table 1, Fig. 3).

The network of phylogenetic relationships between haplotypes revealed three main clades (Fig. 2). The first clade (2-1) contained the haplotypes that were found in 17 individuals of $F$. rufa, 8 of $F$. polyctena, 2 of $F$. lugubris, and all 17 workers from "mixed" colony FM-2. Haplotypes of individuals from colony FM-2 showed strong phylogenetic similarity to a haplotype of individuals of $F$. rufa from which they differed by at most three mutational steps. The second clade (2-2) grouped haplotypes of 4 individuals of $F$. truncorum, 4 of $F$. pratensis, and 2 of $F$. frontalis. The third clade (2-3) contained haplotypes of 17 individuals of $F$. polyctena, 15 of $F$. aquilonia, 6 of $F$. lugubris, 2 of $F$. paralugubris, 1 of $F$. pratensis, and all 15 individuals from "mixed" colony FM-1 (Fig. 2).

Analysis of phylogenetic trees gave similar results. All constructed trees shared a similar topology and confirmed the subdivision of haplotypes of $F$. rufa, $F$. polyctena, and $F$. aquilonia species into two clades (2-1 and 2-3), while species that were in the central clade of the haplotype network (2-2) took a position outside clades 2-1 and 2-3 in all trees (Fig. 3).

We compared allele frequencies at microsatellite loci in two "mixed" colonies with allele frequencies in pure colonies of $F$. rufa, F. polyctena, and $F$. aquilonia (allele frequencies in these groups are given in the Appendix). The number of individuals sampled with the phenotypes of $F$. lugubris, $F$. pratensis or $F$. truncorum was very small (1-2 per colony), and these samples were used only for comparison with $F$. rufa, $F$. polyctena, and $F$. aquilonia.

In both "mixed" colonies, the observed heterozygosity was lower than expected heterozygosity, the inbreeding coefficient $F_{I S}$ was high (Table 2) and Hardy-Weinberg test showed a significant heterozygote deficit $(P<0.05$ in each case). A significant heterozygote deficit and high inbreeding coefficient were recorded for pure colonies of $F$. polyctena, but not pure colonies of two other species (Table 2). A heterozygote deficit and high inbreeding coefficient may reflect inbreeding or multiple gene pools (possibly different species) building up a colony (Wahlund's effect). The test for population differentiation showed a highly significant differentiation of allele frequencies among two "mixed" colonies and pure colonies of $F$. rufa, $F$. polyctena, and $F$. aquilonia $(P<0.00001)$.

Based on allele frequencies at microsatellite loci, we estimated genetic distances, expressed as pairwise $F_{S T}$, between ants grouped according to phenotypes and according to colonies. For phenotypic comparison, ants from both "mixed" and homogeneous colonies were grouped together according to phenotypes of $F$. rufa, $F$. polyctena, and $F$. aquilonia. The genetic distance between $F$. rufa, $F$. polyctena, and $F$. aquilonia phenotypes was relatively small and ranged from 0.06 to 0.08 (Table 3). In contrast, the genetic distance between colonies of the same phenotype was relatively high (0.11-0.29) with values comparable to the genetic dis-

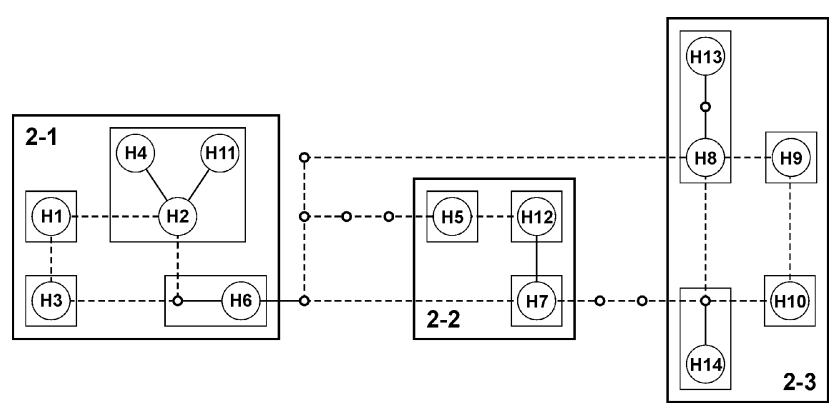

Fig. 2. Statistical parsimony network of the phylogenetic relationships among the Formica mtDNA haplotypes. Circles with numbers represent haplotypes. Each line between two haplotypes represents a single mutational change. Small circles represent interior nodes in the network that were not present in the sample, i.e. these are inferred intermediate haplotypes between two nearest neighbour haplotypes in the network that differed by two or more mutations. Thin line rectangles indicate haplotypes grouped in 1-step clades. Thick line rectangles indicate 1 -step clades grouped in 2-step clades. The haplotypes of $F$. candida were not included in the network because they were connected with the haplotypes of other species by more than 6 mutational steps, which constituted the threshold of the $95 \%$ parsimonious connection. 


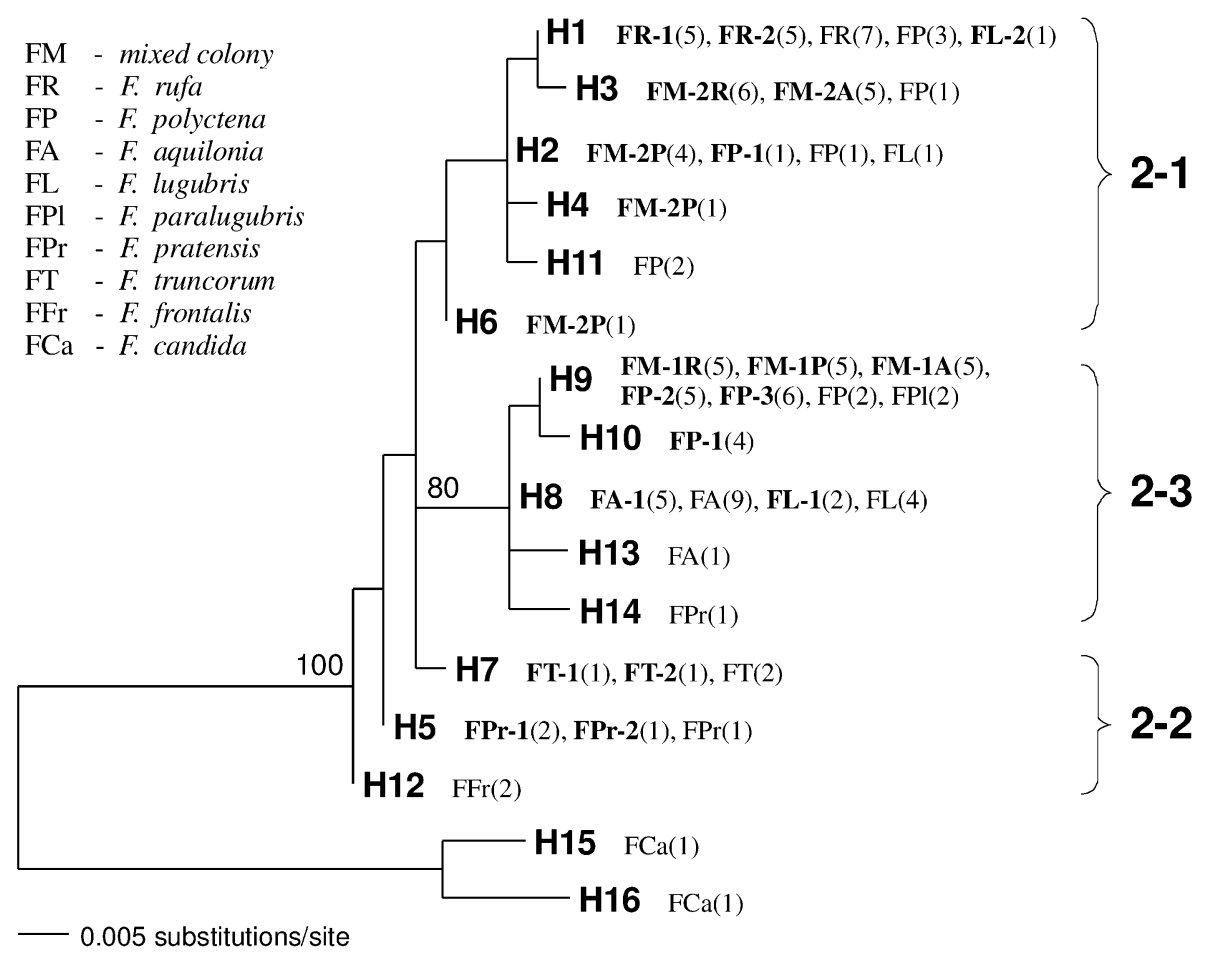

Fig. 3. Maximum likelihood tree generated from $16 \mathrm{mtDNA}$ haplotypes found in the Formica colonies tested (indicated in bold; for abbreviations, see last paragraph of Methods) and orthologous sequences from NCBI database. The number of individuals with a given haplotype is shown in parentheses. Bootstrap values over $50 \%$ are shown for nodes. The numbering of the clades is the same as in Fig. 2.

tance between colonies of different phenotypes (0.13-0.47) (Table 4).

In the case of "mixed" colony FM-2, the genetic distance to the geographically closest $F$. rufa colonies was especially small (FM-2 to FR-2: 0.05, geographic distance $50 \mathrm{~m}$; FM-2 to FR-1: 0.08, geographic distance 40 $\mathrm{m})$. However, the genetic distance between colony FM-2 and the geographically most distant (ca. $2680 \mathrm{~m}$ ) $F$. polyctena colony FP-3 was also small: 0.08 . In the case of "mixed" colony FM-1 the shortest genetic distance $(0.10)$ was to the nearby (ca. $270 \mathrm{~m}) F$. polyctena colony FP-3 (Table 4).

The assignment test performed based on microsatellite data using GeneClass2 assigned all individuals (except one from colony FM-1) to the colony from which they originated. Workers within all the colonies tested, including the "mixed" ones, were more genetically similar to their own colony than to any of the others. Average values of assignment of individuals from particular colonies to their own colony and all other colonies are given in Table 5. All individuals (except one from colony FP-3) originating from phenotypically homogeneous colonies were assigned with the highest probability to a priori groups consisting of individuals of the same morphological phenotype. In "mixed" colony FM-1, all workers with the $F$. rufa phenotype were assigned with the highest probability to the group of individuals with the $F$. polyctena phenotype. In colony FM-2, workers with the $F$. rufa phenotype were assigned either to the group of individuals with the $F$. rufa phenotype or the $F$. aquilonia phenotype. Similarly, workers with the $F$. aquilonia phenotype from colony FM-2 were assigned either to the group of individuals with the $F$. rufa phenotype or the $F$. aquilonia phenotype. Other individuals from "mixed" colonies were assigned to groups consisting of individuals sharing the same morphological phenotype. Average values of assignment of individuals of different phenotypes to a priori groups consisting of individuals of one particular phenotype are given in Table 6.

TABLE 2. Observed heterozygosity $\left(H_{O}\right)$, expected heterozygosity $\left(H_{E}\right)$ and inbreeding coefficient $\left(F_{I S}\right)$ of "mixed" colonies and "pure" colonies of the three species, calculated based on microsatellite data. $P$ - the $P$-value of the Hardy-Weinberg equilibrium test.

\begin{tabular}{lcccc}
\hline Colony, species & $H_{O}$ & $H_{E}$ & $F_{I S}$ & $P$ \\
\hline FM-1 & 0.466667 & 0.546428 & 0.1460 & 0.0500 \\
FM-2 & 0.460784 & 0.554338 & 0.1835 & 0.0002 \\
F. rufa & 0.516667 & 0.521296 & 0.0089 & 0.1473 \\
F. polyctena & 0.509804 & 0.652267 & 0.2184 & 0.0000 \\
F. aquilonia & 0.733333 & 0.475000 & -0.5439 & 0.9908 \\
\hline
\end{tabular}


TABLE 3. Genetic distance $\left(F_{S T}\right)$ between pairs of Formica phenotypes, calculated based on microsatellite data.

\begin{tabular}{|c|c|c|c|c|c|}
\hline Phenotype & F. rufa & $F$. polyctena & F. aquilonia & F. lugubris & F. pratensis \\
\hline F.polyctena & 0.0828 & & & & \\
\hline F. aquilonia & 0.0766 & 0.0636 & & & \\
\hline F. lugubris & 0.1538 & 0.1288 & 0.0761 & & \\
\hline F. pratensis & 0.2405 & 0.2356 & 0.1366 & 0.1604 & \\
\hline F. truncorum & 0.0970 & 0.1024 & 0.0690 & 0.1214 & 0.1080 \\
\hline
\end{tabular}

The test to detect first generation migrants based on allele frequencies at microsatellite loci was performed in two ways: detection of migrants from an alien colony and detection of individuals genetically more similar to individuals of a phenotype other than their own. The test also assigned offspring of migrants to the population from which one or both parents originated, so it could detect workers descending from a male or queen of an alien genotype. Six cases of "migrants", i.e. mis-assigned individuals $(P \leq 0.01)$, between colonies were found (two in colony FM-2 and one in each of colonies FM-1, FR-2, FP-1, and FP-3) and six between phenotypes (two in colony FM-2 and one in each of colonies FM-1, FR-2, FP-2, and FP-3). In general, the test for the detection of first generation migrants assigned individuals in a similar way to the assignment test. In colony FM-1, all individuals with the $F$. rufa phenotype were assigned with the highest probability to the a priori group consisting of individuals with the $F$. polyctena phenotype, and three workers with the $F$. polyctena phenotype were assigned to the group of individuals with the $F$. rufa phenotype. In colony FM-2, all individuals with the $F$. aquilonia phenotype were assigned with the highest probability to the group of individuals with the $F$. rufa phenotype.

The STRUCTURE analysis performed without any prior information about individuals did not indicate any clear population genetic structure. The test based on phenotype gave the most probable population structure consistent with the phenotypic groups. However, two workers from colony FM-1 with the F. rufa phenotype were assigned to the $F$. polyctena phenotype and one worker from colony FM-2 with the $F$. aquilonia phenotype was assigned to the $F$. rufa phenotype. For 7 individuals with the $F$. rufa phenotype (including 5 from "mixed" colony FM-1), 8 with $F$. polyctena (1 from "mixed" colony FM-2), and 3 with $F$. aquilonia (all from FM-2), the probability of assignment to the phenotype in concordance with their morphology was lower than 0.9 .

\section{DISCUSSION}

Analyses of mitochondrial and nuclear DNA confirmed the close phylogenetic relationship between the wood ant species $F$. rufa, F. polyctena, and $F$. aquilonia. This result reflects the strong morphological and behavioural similarity of these species (see e.g. Dlussky, 1967; Dlussky \& Pisarski, 1971; Seifert, 1996b; Czechowski et al., 2002) and corroborates the results of earlier genetic studies (Goropashnaya et al., 2003, 2004). However, the analysis of mtDNA haplotypes indicated relationships among these species different to those established previously. According to Goropashnaya et al. (2003, 2004), F. rufa and $F$. polyctena form a monophyletic group distinct from $F$. aquilonia. In the present study, clade 2-1 corresponded to $F$. rufa and $F$. polyctena, clade 2-2 to $F$. truncorum, $F$. pratensis, and $F$. frontalis, and clade $2-3$ to $F$. aquilonia and $F$. polyctena. Therefore, $F$. rufa and $F$. aquilonia at this southern Finnish location appeared to be clearly distinct with regard to their mtDNA haplotypes, while $F$. polyctena at this location had mtDNA haplotypes that were phylogenetically related to those of local $F$. aquilonia and F. rufa. F. polyctena also showed the highest genetic polymorphism in both nuclear and mitochondrial DNA of the three species studied.

Most of the $F$. rufa-group species are able to interbreed under natural conditions and individuals of intermediate phenotypes between species are frequently observed (Seifert, 1991, 1999; Czechowski, 1993, 1996; Czechowski \& Douwes, 1996; Goropashnaya et al., 2004; Sorvari, 2006). Unusually hairy individuals of $F$. polyctena reported from continental Europe are generally thought to be hybrids of $F$. polyctena and $F$. rufa (Seifert, 1991, 1996b; Czechowski \& Douwes, 1996). On the other hand, Sorvari (2006) considers the hairy morphs of $F$. polyctena from central and southern Finland to be hybrids of $F$. polyctena and $F$. aquilonia. Genetic data confirm the ability of $F$. rufa, $F$. polyctena, and $F$. aquilonia to cross-breed among themselves and with other

TABLE 4. Genetic distance $\left(F_{S T}\right)$ between pairs of Formica colonies, calculated based on microsatellite data.

\begin{tabular}{|c|c|c|c|c|c|c|c|c|c|}
\hline Colony & FM-1 & FM-2 & FR-1 & FR-2 & FP-1 & FP-2 & FP-3 & FA-1 & FL-1 \\
\hline FM-2 & 0.1137 & & & & & & & & \\
\hline FR-1 & 0.2633 & 0.0757 & & & & & & & \\
\hline FR-2 & 0.1125 & 0.0528 & 0.1303 & & & & & & \\
\hline FP-1 & 0.1731 & 0.1774 & 0.3527 & 0.2277 & & & & & \\
\hline FP-2 & 0.2367 & 0.3366 & 0.4745 & 0.3475 & 0.2708 & & & & \\
\hline FP-3 & 0.1028 & 0.0769 & 0.1716 & 0.1255 & 0.1097 & 0.2920 & & & \\
\hline FA-1 & 0.2407 & 0.2448 & 0.4159 & 0.3024 & 0.1967 & 0.3575 & 0.2306 & & \\
\hline FL-1 & 0.2079 & 0.1601 & 0.3225 & 0.2388 & 0.3170 & 0.3918 & 0.0723 & 0.2832 & \\
\hline FPr-1 & 0.3489 & 0.2102 & 0.3160 & 0.2863 & 0.3395 & 0.5281 & 0.1430 & 0.3636 & 0.1538 \\
\hline
\end{tabular}


TABLE 5. Average values of assignment of individuals from particular colonies (rows) to all colonies from which more than one individual was sampled. The highest values are indicated in bold. These results were obtained based on microsatellite data using the program GeneClass.

\begin{tabular}{|c|c|c|c|c|c|c|c|c|c|c|}
\hline Colony & FM-1 & FM-2 & FR-1 & FR-2 & FP-1 & FP-2 & FP-3 & FA-1 & FL-1 & FPr-1 \\
\hline FM-1 & 0.55 & 0.10 & 0.00 & 0.08 & 0.04 & 0.00 & 0.10 & 0.00 & 0.01 & 0.00 \\
\hline FM-2 & 0.02 & 0.51 & 0.03 & 0.06 & 0.01 & 0.00 & 0.10 & 0.00 & 0.02 & 0.00 \\
\hline FR-1 & 0.00 & 0.15 & 0.70 & 0.07 & 0.00 & 0.00 & 0.04 & 0.00 & 0.00 & 0.00 \\
\hline FR-2 & 0.09 & 0.06 & 0.01 & 0.59 & 0.01 & 0.00 & 0.03 & 0.00 & 0.04 & 0.00 \\
\hline FP-1 & 0.01 & 0.03 & 0.00 & 0.01 & 0.71 & 0.00 & 0.20 & 0.01 & 0.00 & 0.00 \\
\hline FP-2 & 0.01 & 0.00 & 0.00 & 0.00 & 0.07 & 0.64 & 0.02 & 0.00 & 0.00 & 0.00 \\
\hline FP-3 & 0.00 & 0.03 & 0.00 & 0.01 & 0.02 & 0.00 & 0.68 & 0.00 & 0.03 & 0.00 \\
\hline FA-1 & 0.00 & 0.01 & 0.00 & 0.00 & 0.09 & 0.00 & 0.00 & 0.83 & 0.02 & 0.00 \\
\hline FL-1 & 0.00 & 0.00 & 0.00 & 0.00 & 0.00 & 0.00 & 0.09 & 0.00 & 0.96 & 0.10 \\
\hline FPr-1 & 0.00 & 0.00 & 0.00 & 0.00 & 0.06 & 0.00 & 0.11 & 0.00 & 0.52 & 0.92 \\
\hline
\end{tabular}

Formica s. str. species (Goropashnaya et al., 2004; Gyllenstrand et al., 2004; Seifert \& Goropashnaya, 2004). The incomplete reproductive isolation of these species can be explained by their relatively recent speciation, which took place during the Pleistocene (Pamilo et al., 1979; Vepsäläinen \& Pisarski, 1981; Collingwood \& Agosti, 1986; Goropashnaya et al., 2004). Nevertheless, the frequency of hybrids is strongly differentiated geographically and may be very high locally (Seifert, 1991, 1999; Seifert \& Goropashnaya, 2004). Particularly noticeable is the morphological ambiguity of workers of the $F$. rufa-group species, particularly $F$. polyctena and $F$. aquilonia, often observed in northern Europe (Gösswald et al., 1965; Rosengren, 1977a, b; Collingwood, 1979; Douwes, 1979; Pamilo et al., 1979, 1992; Vepsäläinen \& Pisarski, 1981), which suggests that very frequent hybridisation may occur between these species. The region of southern Finland investigated in the present study is particularly well known to myrmecologists for the unusually frequent and often inexplicable variability among $F$. rufa-group species, represented there by $F$. rufa, $F$. polyctena, $F$. aquilonia, and F. lugubris (see e.g. Czechowski, 1996). The remarkable morphological spectrum seen here sug- gests hybridisation within the local wood ant species and/or the existence of multi-species colonies (e.g. Pamilo \& Vepsäläinen, 1977; Pamilo et al., 1979).

Analyses of mitochondrial and nuclear DNA did not confirm the hypothesis that workers exhibiting different phenotypes belonging to the same "mixed" colonies constitute a conglomeration of individuals of three different species, as suggested in a previous paper based on morphological key features (Czechowski \& Radchenko, 2006). All but one of the workers investigated from the two "mixed" colonies were assigned with the highest probability to the colony from which they originated. Therefore, independently of their phenotype, workers from the "mixed" colonies were genetically more similar to workers in their own colony than to those in any of the homogeneous $F$. rufa, $F$. polyctena, or $F$. aquilonia colonies. In other words, individuals from the same "mixed" colony, even those of different phenotypes, were evidently related.

In "mixed" colony FM-1 the $F$. polyctena phenotype prevailed, that of $F$. aquilonia was less frequent, while the number of individuals with the F. rufa phenotype was very low. All individuals from this colony had the same

TABLE 6. Average values of assignment of individuals of different phenotypes (rows) to a priori groups consisting of individuals with one particular phenotype: F. rufa, F. polyctena, F. aquilonia, F. lugubris, $F$. pratensis or $F$. truncorum. The highest values (and second highest values if $>0.5$ ) are indicated in bold. These results were obtained based on microsatellite data using the program GeneClass.

\begin{tabular}{lcccccc}
\hline Phenotype & F.rufa & F. polyctena & F. aquilonia & F. lugubris & F. pratensis & F. truncorum \\
\hline FM-1R & 0.33 & $\mathbf{0 . 6 0}$ & 0.00 & 0.01 & 0.00 & 0.04 \\
FM-2R & $\mathbf{0 . 6 7}$ & 0.10 & $\mathbf{0 . 5 3}$ & 0.02 & 0.00 & 0.15 \\
FR-1 & $\mathbf{0 . 6 5}$ & 0.06 & 0.05 & 0.02 & 0.00 & 0.09 \\
FR-2 & $\mathbf{0 . 4 6}$ & 0.04 & 0.25 & 0.16 & 0.00 & 0.09 \\
FM-1P & 0.49 & $\mathbf{0 . 6 5}$ & 0.02 & 0.01 & 0.00 & 0.07 \\
FM-2P & 0.02 & $\mathbf{0 . 3 7}$ & 0.11 & 0.06 & 0.00 & 0.01 \\
FP-1 & 0.00 & $\mathbf{0 . 4 9}$ & 0.01 & 0.00 & 0.00 & 0.01 \\
FP-2 & 0.01 & $\mathbf{0 . 3 2}$ & 0.00 & 0.00 & 0.00 & 0.02 \\
FP-3 & 0.00 & $\mathbf{0 . 2 3}$ & 0.00 & 0.04 & 0.00 & 0.03 \\
FM-1A & 0.01 & 0.04 & $\mathbf{0 . 6 6}$ & 0.05 & 0.00 & 0.01 \\
FM-2A & $\mathbf{0 . 6 1}$ & 0.09 & $\mathbf{0 . 6 2}$ & 0.05 & 0.00 & 0.31 \\
FA-1 & 0.00 & 0.06 & $\mathbf{0 . 5 9}$ & 0.04 & 0.00 & 0.01 \\
FL-1 + FL-2 & 0.09 & 0.05 & 0.16 & $\mathbf{0 . 9 1}$ & 0.02 & 0.07 \\
FPr-1 + FPr-2 & 0.00 & 0.05 & 0.16 & 0.29 & $\mathbf{0 . 7 7}$ & 0.23 \\
FT-1 + FT-2 & 0.02 & 0.15 & 0.05 & 0.10 & 0.00 & $\mathbf{0 . 9 9}$ \\
\hline
\end{tabular}


haplotype. Therefore, the workers could be the offspring of one queen (possibly mated with males of different species or with hybrid males) or of several queens that were maternal kin. Nevertheless, the explosive growth of this colony (see Czechowski \& Radchenko, 2006) strongly suggests that FM-1 enlarged its pool of fertilised queens at some point, perhaps after the death of the foundress. It is known that orphaned (queenless) wood ant colonies are capable of adopting new queens, making their continued existence possible (Pisarski \& Czechowski, 1994). Indeed, their workers can even take the initiative to actively recruit new queens (see Czechowski, 1994).

It is very unlikely that colony FM-1, which was probably three years old at the time, was able to produce its own sexuals, so the most reliable explanation is that this colony adopted some foreign queens. They may have been derived from a polydomus $F$. polyctena colony on a neighbouring island. This colony included the nest FP-3 (see Fig. 1), which possessed the same mtDNA haplotype as colony FM-1. The small genetic distance between colonies FM-1 and FP-3 supports this possibility.

The haplotype of colony FM-1 clustered in the clade of $F$. polyctena and $F$. aquilonia to which no $F$. rufa haplotype was affiliated. All workers of the $F$. rufa phenotype were assigned to the $F$. polyctena phenotype based on their microsatellite genotype. Thus, in colony FM-1 the individuals with the $F$. rufa phenotype were genetically closer to $F$. polyctena than to $F$. rufa. Hybrid ants can have phenotypes intermediate between those of the parental species (Pearson, 1983; Seifert, 1984, 1991, 1999) or a phenotype typical of one of the parents (Seifert \& Goropashnaya, 2004). Therefore, the genetic data did not allow us to reject the possibility that in colony FM-1 the workers with the $F$. rufa phenotype descended from queens that were $F$. polyctena $\times F$. aquilonia hybrids. The colony FM-1 could also contain both $F$. polyctena $\times F$. aquilonia and $F$. polyctena $\times F$. rufa hybrid queens, or alternatively the queens were second generation hybrids $F$. polyctena $\times F$. aquilonia $\times F$. rufa. The colony produced males with $F$. aquilonia and $F$. polyctena/F. rufa phenotypes (males of the latter two species are morphologically indistinguishable). During the nuptial flight, cases of copulation were observed on the FM-1 mound surface (W. Czechowski, unpubl.), which indicates that the local queens might have been fertilised by their brothers and/or nephews. This indicates high inbreeding and suggests a potential mechanism by which the high incidence of hybrids is maintained in this colony.

In the second "mixed" colony, FM-2, the F. rufa phenotype prevailed, that of $F$. polyctena was represented by fewer individuals, while the incidence of the $F$. aquilonia phenotype was very low. Four haplotypes occurred in this colony, which indicated that it consisted of individuals descending from at least four unrelated queens. Despite this multiple origin, the results of the assignment test suggest that these individuals were more related to each other than to individuals from other colonies belonging to their respective phenotypic groups. This suggests that all these individuals were related in the paternal line, e.g. as a result of copulation of queens with males from the same colony.

All haplotypes that occurred in colony FM-2 clustered in the clade of $F$. rufa and $F$. polyctena, to which no $F$. aquilonia haplotype was affiliated. All workers with the $F$. aquilonia phenotype had the same haplotype as the workers with the F. rufa phenotype. Most of the workers with the $F$. polyctena phenotype had the same haplotype as that occurring in the nearby $F$. polyctena colony FP-1. In FM-2, some individuals with the $F$. aquilonia phenotype were assigned to the $F$. rufa phenotype and some individuals with the $F$. rufa phenotype to the $F$. aquilonia phenotype based on their microsatellite genotypes. Therefore, in colony FM-2 the workers with the $F$. aquilonia phenotype were genetically closer to $F$. rufa than to $F$. aquilonia. Topographically, "mixed" colony FM-2 was situated very close to the $F$. rufa colonies FR-1 and FR-2 and the genetic distance between them was also very small. This suggests that in colony FM-2 the workers with the $F$. aquilonia phenotype could have descended from queens that were $F$. rufa $\times F$. polyctena hybrids. Nevertheless, it is very unlikely that $F$. polyctena $\times F$. rufa hybrid workers could exhibit the more hairy phenotype of $F$. aquilonia. Probably colony FM-2 (as well as FM-1) contained both $F$. polyctena $\times F$. aquilonia and $F$. polyctena $\times F$. rufa hybrid queens, or the queens were $F$. polyctena $\times F$. aquilonia $\times F$. rufa hybrids.

The cases of "mixed" colonies FM-1 and FM-2 clearly differed; colony FM-1 consisted of individuals that were the offspring of the same queen or (more probably) several queens related maternally, while colony FM-2 consisted of individuals that were descendents of at least four unrelated queens. However, the most likely mechanism leading to the existence of both these colonies was the same: hybridisation between the species of the $F$. rufagroup leading to the existence of fertile(!) hybrids. This finding adds strong support to the hypothesis that speciation is not complete in the $F$. rufa-group (Goropashnaya et al., 2004). F. polyctena, F. aquilonia, and F. rufa are not reciprocally monophyletic with regard to mtDNA haplotypes, which may be due to incomplete lineage sorting. Hybridisation followed by introgression of mtDNA haplotypes may provide an alternative explanation of this fact. It is already known that many species of ants readily interbreed and produce viable and fertile offspring under laboratory conditions (Buschinger, 2001). The present study demonstrates that wood ant colonies composed of hybrids can exist permanently, or at least for many years, under natural conditions, and that these hybrids may morphologically resemble specific representatives of the $F$. rufa-group ( $F$. rufa, F. polyctena, $F$. aquilonia) or more or less intermediate forms $(F$. rufa/F. polyctena $)$.

Fertility of hybrids between $F$. rufa-group species, which is strongly suggested by the results of this preliminary study and the likely mechanism of appearance of these hybrids, discussed here in the light of the findings of this and a previous study (Czechowski \& Radchenko, 2006), underlie the phenomenon of "mixed" colonies. The above hypothesis requires step-by-step factual verifi- 
cation, a task that is undoubtedly complex and time consuming. Further research on hybridisation in wood ants and other ant genera, carried out on larger sample sizes, is required to determine the mechanisms underlying this phenomenon and assess the frequency, circumstances and determinants of its occurrence.

In all the colonies studied, both "mixed" and homogeneous, only individuals with species-specific morphological features, i.e. those manifesting no intermediate traits, were analysed. However, genetic differences between workers were not always associated with differences in their morphology. The ants of the same phenotype with different haplotypes and individuals of the same haplotype but with different phenotypes were found both in homogenous and heterogeneous colonies. Analysis of nuclear DNA showed that workers more genetically similar to individuals of a phenotype different from their own (probably hybrids) occurred not only in the "mixed" colonies, but also in colonies that were morphologically recognised as "pure" $F$. polyctena or $F$. rufa. This finding indicates the possible presence of some admixture of cross-mated or even hybrid queens in queen pools of the polygynous, apparently homospecific colonies of these species.

Seifert \& Goropashnaya (2004) point out that mitochondrial DNA studies may frequently result in the misidentification of wood ants. They suggest that in this species group, in which there is a very high frequency of interspecific hybridisation, nuclear DNA conformed better than mtDNA with the morphological identification of species. However, our study shows incongruence between morphological and both mitochondrial and nuclear DNA data.

Our results reveal that the identification of species of closely related and frequently interbreeding species of ants based solely on genetic analysis may lead to confusing results. Caution is needed, particularly when the genetic analyses are based on small samples, a short DNA sequence or a small number of microsatellite loci. On the other hand, the species status of some colonies is indeterminable based on morphological criteria. In such cases a combination of genetic, morphological, and ecological studies is recommended.

ACKNOWLEDGEMENTS. The genetic study was financially supported by the UNESCO/Polish Academy of Sciences Cellular and Molecular Biology Network (grant assigned to J.K). M.P. was supported by the Foundation for Polish Science. The preceding field investigations were carried out within the program of scientific co-operation between the Polish Academy of Sciences and the Academy of Finland. W.C. and A.R. are grateful to the staff of the Tvärminne Zoological Station of the University of Helsinki for their support during the fieldwork and for providing a splendid environment for this study, and to $\mathrm{K}$. Vepsäläinen for numerous invitations to visit Finland. All the authors are grateful to K. Vepsäläinen for his critical review of this manuscript and many helpful suggestions.

\section{REFERENCES}

Beretta Boera M., Petrazzini S., Pavan M. \& Troconi A. (eds) 1979: Comptes Rendus de la Réunion des Groupes de Travail
"Formica rusa" et "Vertébrés Prédateurs des Insectes" de l'OILB (Varenna, Italie, 1978). Bulletin SROP, II-3. 514 pp.

Buschinger A. 2001: Multiple Hybridisierung von Arten der Ameisen-Gattung Epimyrma (Hymenoptera: Formicidae), und Beobachtungen zur Ausbeutung der Wirtsarten durch die Parasiten. Myrmecol. Nachr. 4: 25-35.

Clement M., Posada D. \& Crandall K.A. 2000: TCS: A computer program to estimate gene genealogies. Mol. Ecol. 9: 1657-1660.

Collingwood C.A. 1979: The Formicidae (Hymenoptera) of Fennoscandia and Denmark. Fauna Entomol. Scand. 8: $1-174$.

Collingwood C.A. \& Agosti D. 1986: Taxonomy and zoogeography of the Formica rufa species group. Supplement to the Workshop "Taxonomy and Zoogeography of the Formica rufa Species Group" Held at the $10^{\text {th }}$ International Congress of IUSSI, Munich, 1986.

Cотті G. 1963: Bibliografia Ragionata 1930-1961 del Gruppo Formica rufa. Collana Verde 8. Ministero dell'Agricoltura e Foreste, Roma, iv +413 pp. [in Italian, German, English].

Czechowski W. 1993: Hybrids in red wood ants (Hymenoptera, Formicidae). Ann. Zool. 44: 43-54.

Czechowski W. 1994: Queen recruitment in an orphaned colony of Formica polyctena Foerst. (Hymenoptera, Formicidae). Ann. Zool. 45: 47-49.

Czechowski W. 1996: Colonies of hybrids and mixed colonies; interspecific nest takeover in wood ants (Hymenoptera, Formicidae). Memor. Zool. 50: 1-116.

Czechowski W. \& Douwes P. 1996: Morphometric characterics of Formica polyctena Foerst. and Formica rufa L. (Hymenoptera, Formicidae) from the Gorce Mts; Interspecific variations. Ann. Zool. 46: 125-141.

Czechowski W., Radchenko A. \& Czechowska W. 2002: The Ants (Hymenoptera, Formicidae) of Poland. Museum and Institute of Zoology PAS, Warsaw, $200 \mathrm{pp}$.

Czechowski W. \& Radchenko A. 2006: Do permanently mixed colonies of wood ants (Hymenoptera: Formicidae) really exist? Ann. Zool. 56: 667-673.

Duussky G.M. 1967: The Ants of the Genus Formica. Nauka, Moskva, 236 pp. [in Russian].

Dlussky G.M. \& Pisarski B. 1971: Revision of Polish ant species of the genus Formica L. (Hymenoptera, Formicidae) Fragm. Faun. 16: 145-224 [in Polish, English abstr.].

DouwEs P. 1979: Formica rufa-gruppens systematic. Entomol. Tidskr. 100: 187-191.

Douwes P. 1981: Intraspecific and interspecific variation in workers of the Formica rufa group (Hymenoptera: Formicidae) in Sweden. Entomol. Scand. (Suppl.) 15: 213-223.

Felsenstein J. 1985: Confidence limits on phylogenies: an approach using the bootstrap. Evolution 39: 783-791.

Goropashnaya A., Seifert B. \& Pamilo P. 2003: Phylogenetic relationships of Palaearctic species (Hymenoptera, Formicidae) based on mitochondrial cytochrome b sequences. Comprehensive Summaries of Uppsala Dissertations from the Faculty of Science and Technology, Paper I. 15 pp.

Goropashnaya A., Fedorov V. \& Pamilo P. 2004: Recent speciation in the Formica rufa group ants (Hymenoptera, Formicidae): inference from mitochondrial DNA phylogeny. Mol. Phylogen. Evol. 32: 198-206.

Goudet J., Raymond M., De Meeus T. \& Rousset F. 1996: Testing differentiation in diploid populations. Genetics 144: 1933-1940.

Gösswald K. 1989: Die Waldameise. Band 1. Biologische Grundlagen, Okologie und Verhalten. Aula, Wiesbaden, xi + 660 pp. 
Gösswald K., Kneitz G. \& Schirmer G. 1965: Die geographische Verbreitung der hügelbauenden Formica-Arten (Hym., Formicidae) in Europa. Zool. Jb. Syst. 92: 369-404.

Gyllenstrand N., Gertsch P.J. \& Pamilo P. 2002: Polymorphic microsatellite DNA markers in the ant Formica exsecta. Mol. Ecol. Notes 2: 67-69.

Gyllenstrand N., Seppä P. \& Pamilo P. 2004: Genetic differentiation in sympatric wood ants, Formica rufa and Formica polyctena. Insectes Soc. 51: 139-145.

KuTTER H. 1977: Hymenoptera, Formicidae. In: Insecta. Helvetica Fauna 6. Schweizerische Entomologische Gesellschaft: Zürich, $297 \mathrm{pp}$.

NeI M. 1978: Estimation of average heterozygosity and genetic distance from a small number of individuals. Genetics 89: 583-590.

Paetkau D., Slade R., Burden M. \& Estoup A. 2004: Genetic assignment methods for the direct, real-time estimation of migration rate: a simulation-based exploration of accuracy and power. Mol. Ecol. 13: 55-65.

PAMILO P. \& VePSÄLÄINEN K. 1977: Heretical notes on the taxonomy of Formica s. str. (Hym.). Proceedings of the VIII International Congress of IUSSI. Wageningen, pp. 128-129.

Pamilo P., Vepsäläinen K., Rosengren R., Varvio-Aho S.-L. \& PISARSKI B. 1979: Population genetics of Formica ants II. Genic differentiation between species. Ann. Entomol. Fenn. 45: $65-76$.

Pamilo P., Chautems D. \& Cherix D. 1992: Genetic differentiation of disjunct populations of the ants Formica aquilonia and Formica lugubris in Europe. Insectes Soc. 39: 15-29.

Pearson B. 1983: Hybridisation between Lasius niger and Lasius alienus. Insectes Soc. 30: 402-411.

Piry S., Alapetite A., Cornuet J.-M., Paetkau D., Baudouin L. \& Estoup A. 2004: GeneClass2: a software for genetic assignment and first generation migrants detection. J. Hered. 95: 536-539.

Pisarski B. \& Czechowski W. 1994: Ways to reproductive success of wood ant queens. Memor. Zool. 48: 181-186.

Posada D. \& Crandall K.A. 1998: MODELTEST: testing the model of DNA substitution. Bioinformatics 14: 817-818.

Pritchard J. K., Stephens M. \& Donnelly P. 2000: Inference of population structure using multilocus genotype data. Genetics 155: 945-959.

Rannala B. \& Mountain J.L. 1997: Detecting immigration by using multilocus genotypes. PNAS 94: 9197-9221.

RAYMOND M. \& Rousset F. 1995: An exact test for population differentiation. Evolution 49: 1280-1283.

ROSENGREN R. 1977a: Foraging strategy of wood ants (Formica rufa group). I. Age polyethism and topographic traditions. Acta Zool. Fenn. 149: 1-30.

Rosengren R. 1977b: Foraging strategy of wood ants (Formica rufa group). II. Nocturnal orientation and diel periodicity. Acta Zool. Fenn. 150: 1-30.
SEIFERT B. 1984: Nachweis einer im Freiland aufgetretenen Bastardierung von Leptothorax nigriceps Mayr und Leptothorax unifasciatus (Latr.) mittels einer multiplen Diskriminanzanalyse. Abh. Ber. Naturkundemus. Görlitz 58: 1-8.

SEIFERT B. 1991: The phenotypes of the Formica rufa complex in East Germany. Abh. Ber. Naturkundemus. Görlitz 65: $1-27$.

SEIFERT B. 1996a: Formica paralugubris nov. spec. - a sympatric sibling species of Formica lugubris from the western Alps (Insecta: Hymenoptera: Formicoidea: Formicidae). Reichenbachia 31: 193-201.

SEIFERT B. 1996b: Ameisen: Beobachten, Bestimmen. Nachtbuch, Augsburg, 352 pp.

SEIFERT B. 1999: Interspecific hybridizations in natural populations of ants by example of a regional fauna (Hymenoptera, Formicidae). Insectes Soc. 46: 45-52.

Seifert B. \& Goropashnaya A. 2004: Ideal phenotypes and mismatching haplotypes - errors of mtDNA treeing in ants (Hymenoptera, Formicidae) detected by standardized morphometry. Organ. Diver. Evol. 4: 295-305.

SoRVARI J. 2006: Two distinct morphs in the wood ant Formica polyctena in Finland: a result of hybridisation? Entomol. Fenn. 17: 1-7.

Swofford D.L. 1998: PAUP Phylogenetic Analysis Using Parsimony and Other Methods. Sinauer Associates, Sunderland, MA.

Templeton A.R. \& Sing C.F.A. 1993: A cladistic analysis of phenotypic associations with haplotypes inferred from restriction endonuclease mapping. IV. Nested analysis with cladogram uncertainty and recombination. Genetics 134: 659-669.

Templeton A.R., Crandall K.A. \& Sing C.F.A. 1992: A cladistic analysis of phenotypic associations with haplotypes inferred from restriction endonuclease mapping and DNA sequence data. III. Cladogram estimation. Genetics 132: 619-633.

Thompson J.D., Higgins D.G. \& Gibson T.J. 1994: CLUSTAL $\mathrm{W}$ : improving the sensitivity of progressive multiple sequence alignment through sequence weighting position-specific gap penalties and weight matrix choice. Nucl. Acid Res. 22: 4673-4680.

Tinaut A. \& Martínez M.D. 1998: Taxonomy and distribution of Formica dusmeti Emery, 1909 and of F. frontalis Santschi, 1919 (Hymenoptera, Formicidae). Graellsia 54: 31-41.

VepsäläInEN K. \& PISARSKI B. 1981: The taxonomy of the Formica rufa group: chaos before order. In Howse P.E. \& Clément J.-L. (eds): Biosystematics of Social Insects. Academi Press, New York, pp. 27-36.

YARROw I.H.H. 1955: The British ants allied to Formica rufa L. (Hym., Formicidae). Trans. Soc. Br. Entomol. 12: 1-48.

Received February 10, 2009; revised and accepted December 9, 2009 
APPENDIX. Microsatellite frequencies for "mixed" colonies and the Formica phenotypic groups studied. FM-1 - "mixed" colony 1; FM-2 - "mixed" colony 2; FR - F. rufa; FP $-F$. polyctena; FA $-F$. aquilonia; FL $-F$. lugubris; $\mathrm{FPr}-F$. pratensis; FT $-F$. truncorum; $\mathrm{N}_{\mathrm{A}}$ - number of alleles at a given locus; $\mathrm{N}_{\Sigma}$ - total numbers of alleles found at all the loci tested; $\mathrm{n}$ - number of individuals; $\mathrm{c}-$ number of colonies.

\begin{tabular}{|c|c|c|c|c|c|c|c|c|c|}
\hline Locus & Allele ${ }^{a}$ & $\begin{array}{c}\text { FM-1 } \\
\mathrm{n}=15 \\
\mathrm{c}=1\end{array}$ & $\begin{array}{c}\mathrm{FM}-2 \\
\mathrm{n}=17 \\
\mathrm{c}=1\end{array}$ & $\begin{array}{c}\text { FR } \\
\mathrm{n}=10 \\
\mathrm{c}=2\end{array}$ & $\begin{array}{c}\mathrm{FP} \\
\mathrm{n}=12 \\
\mathrm{c}=3\end{array}$ & $\begin{array}{c}\text { FA } \\
\mathrm{n}=5 \\
\mathrm{c}=1\end{array}$ & $\begin{array}{c}\text { FL } \\
\mathrm{n}=3 \\
\mathrm{c}=2\end{array}$ & $\begin{array}{c}\mathrm{FPr} \\
\mathrm{n}=3 \\
\mathrm{c}=2\end{array}$ & $\begin{array}{c}\text { FT } \\
n=2 \\
c=2\end{array}$ \\
\hline \multirow{7}{*}{ FE8 } & 298 & - & - & 0.050 & - & - & - & - & - \\
\hline & 308 & - & - & - & 0.118 & 0.100 & - & - & - \\
\hline & 310 & 0.933 & 0.529 & 0.350 & 0.588 & 0.500 & 0.500 & - & - \\
\hline & 312 & 0.033 & 0.412 & 0.600 & 0.294 & 0.400 & 0.500 & 1.000 & 1.000 \\
\hline & 318 & - & 0.059 & - & - & - & - & - & - \\
\hline & 322 & 0.033 & - & - & - & - & - & - & - \\
\hline & $\mathrm{N}_{\mathrm{A}}$ & 3 & 3 & 3 & 3 & 3 & 2 & 1 & 1 \\
\hline \multirow{6}{*}{ FE13 } & 190 & - & 0.088 & - & 0.147 & - & 0.333 & 0.167 & - \\
\hline & 193 & 0.533 & 0.353 & 0.500 & 0.235 & - & - & - & 0.500 \\
\hline & 196 & 0.167 & 0.088 & - & 0.118 & 0.900 & 0.333 & 0.667 & 0.500 \\
\hline & 199 & 0.167 & 0.294 & 0.500 & 0.088 & - & 0.333 & - & - \\
\hline & 202 & 0.133 & 0.176 & - & 0.412 & 0.100 & - & 0.167 & - \\
\hline & $\mathrm{N}_{\mathrm{A}}$ & 4 & 5 & 2 & 5 & 2 & 3 & 3 & 2 \\
\hline \multirow{14}{*}{ FE16 } & 155 & - & - & - & 0.088 & - & - & - & 0.500 \\
\hline & 157 & - & 0.176 & - & 0.029 & 0.500 & - & - & - \\
\hline & 159 & - & - & - & 0.118 & - & 0.500 & 0.667 & 0.250 \\
\hline & 161 & 0.200 & 0.294 & - & 0.029 & - & - & 0.333 & 0.250 \\
\hline & 163 & - & - & - & 0.265 & - & - & - & - \\
\hline & 165 & - & - & - & 0.088 & - & - & - & - \\
\hline & 167 & 0.133 & - & 0.300 & - & - & - & - & - \\
\hline & 169 & - & - & 0.100 & - & 0.500 & 0.500 & - & - \\
\hline & 171 & 0.533 & 0.029 & 0.100 & 0.235 & - & - & - & - \\
\hline & 173 & 0.133 & 0.088 & - & 0.088 & - & - & - & - \\
\hline & 175 & - & 0.294 & 0.050 & 0.029 & - & - & - & - \\
\hline & 177 & - & 0.118 & 0.200 & 0.029 & - & - & - & - \\
\hline & 179 & - & - & 0.250 & - & - & - & - & - \\
\hline & $\mathrm{N}_{\mathrm{A}}$ & 4 & 6 & 6 & 10 & 2 & 2 & 2 & 3 \\
\hline \multirow{8}{*}{ FE17 } & 113 & - & - & - & 0.059 & - & - & - & - \\
\hline & 117 & - & - & - & 0.059 & - & - & - & - \\
\hline & 119 & 0.500 & 0.500 & 0.400 & 0.471 & 0.500 & 0.333 & - & 0.500 \\
\hline & 121 & 0.333 & 0.471 & 0.500 & 0.265 & - & 0.500 & 0.500 & 0.500 \\
\hline & 123 & 0.167 & 0.029 & - & 0.029 & 0.500 & 0.167 & 0.500 & - \\
\hline & 125 & - & - & 0.050 & 0.118 & - & - & - & - \\
\hline & 127 & - & - & 0.050 & - & - & - & - & - \\
\hline & $\mathrm{N}_{\mathrm{A}}$ & 3 & 3 & 4 & 6 & 2 & 3 & 2 & 2 \\
\hline \multirow{9}{*}{ FE37 } & 113 & - & 0.029 & - & 0.029 & - & - & - & - \\
\hline & 117 & 0.267 & 0.118 & - & 0.059 & 0.200 & - & 0.333 & - \\
\hline & 119 & 0.433 & 0.441 & 0.500 & 0.735 & 0.700 & - & 0.333 & 0.500 \\
\hline & 121 & 0.267 & 0.412 & 0.400 & 0.088 & - & 0.833 & 0.167 & 0.500 \\
\hline & 123 & - & - & - & - & 0.100 & 0.167 & 0.167 & - \\
\hline & 125 & 0.033 & - & 0.050 & 0.059 & - & - & - & - \\
\hline & 127 & - & - & 0.050 & - & - & - & - & - \\
\hline & 135 & - & - & - & 0.029 & - & - & - & - \\
\hline & $\mathrm{N}_{\mathrm{A}}$ & 4 & 4 & 4 & 6 & 3 & 2 & 4 & 2 \\
\hline \multirow{4}{*}{ FE42 } & 261 & 0.633 & 0.971 & 1.000 & 0.441 & 0.500 & 0.667 & 1.000 & 0.500 \\
\hline & 263 & 0.367 & 0.029 & & 0.529 & 0.500 & 0.333 & - & 0.500 \\
\hline & 265 & - & - & & 0.029 & - & - & - & - \\
\hline & $\mathrm{N}_{\mathrm{A}}$ & 2 & 2 & 1 & 3 & 2 & 2 & 1 & 2 \\
\hline \multicolumn{2}{|c|}{$\mathrm{N}_{\Sigma}$} & 20 & 23 & 20 & 33 & 14 & 14 & 13 & 12 \\
\hline
\end{tabular}

${ }^{\mathrm{a}}$ Numbers indicate the number of base pairs in each allele. 